\title{
Leadership in Community Public-Private Partnership Health and Social Care Initiatives
}

\author{
Hawa Yatera Mshana \\ Walden University \\ Magdeline Aagard \\ Walden University \\ Cheryl Cullen \\ Walden University \\ Patrick A. Tschida \\ Walden University
}

\begin{abstract}
Although the public-private partnerships in health have been adopted as the best pathway to improving health outcomes in many developing nations, implementation lacks collaborative leadership. The purpose of this empirical qualitative case study was to determine key factors that promote leadership synergy (LS) between partners that enhance ownership and accountability of community health and social initiatives in Tanzania. The diffusion of innovation theory and public-private integrated partnership module were the theoretical framework guided this study. Diffusion of innovation theory is based on the importance of effective communication to spread new ideas and foster change in behavior in a social group such as public and private partnership integrations (Roger, 2003). Twenty-six participants responded to in-depth, one-on-one interviews and the related documents were reviewed. With the use of directed content analysis and NVivo program, six themes emerged. Findings confirmed that integrated supportive supervision, teamwork, and strategic communications promote partnership LS. On the other hand, findings also showed that unclear roles and responsibilities, weak data, and limited understanding of the benefits of public-private partnerships at the community level hinder ownership and accountability. The potential positive social change of this study includes improving LS that promotes community leader engagement and ultimately improving access and use of community health and social programs in Tanzania.
\end{abstract}

Keywords: public-private partnership, leadership synergy, collaborative leadership, partnership leadership synergy, strategic communication, teamwork, supportive supervision

\section{Introduction}

The public-private partnership (PPP) leadership synergy (LS) approach is required to enhance ownership and accountability of health and social care initiatives in Tanzania. The idea of PPP in health in the developing nations was to improve health outcomes of the population (Spreng, 2011;

We wish to thank the Walden University for the entire academic and research guidance that enabled us to share the findings of this article. In particular, we thank Dr. Cheryl Cullen, Dr. Magdeline Aagard, and Dr. Patrick Tshida at Walden University Public Health Department for their enormous insightful advice and review of this research. We express gratitude and appreciation to Dr. Mark Gordon of the School of Public Health and Administration at Walden University for the editorial review of this article. 
Sturchio \& Cohen, 2012; World Health Organization, 2016). LS is a coalition force between public and private partners to influence accountability through active communication, shared values and collaboration for the delivery of health and social care services (Jones \& Barry, 2011). Public health leaders represent the voices and the needs of the citizens and are accountable for the delivery of health and social care services (Crosby \& Bryson, 2010; Weiss, Taber, Breslau, Lillie \& Li, 2010). Lack of accountability on PPP leadership and lack of community engagement require a synergistic approach between public and private sectors to improve the health and social welfare of the population (Cramm, Phaff, \& Nieboer, 2013; Curry, Taylor, Chi-Chen \& Bradley, 2012; Jones \& Barry, 2011).

In Tanzania, the PPP concept has been adapted to foster collaboration and accountability to deliver continuity of health services and improve the quality of and access to health and social care (Kikuli \& Mbando, 2011; Sekhiri, Feachem, \& Ni, 2011; White et al, 2013). Despite the implementation of PPP in health care, there is limited understanding of the social determinant of health and significant gap in leadership coordination on PPPs health and social care initiatives (Curry et al., Cramm et al., 2013; Itika, Mashindano \& Kessy, 2011; Kwesigabo, Mwangu, Kakoko, \& Killewo, 2012).

Preventable health conditions associated with child and maternal mortality, HIV, tuberculosis, malnutrition, malaria, and poverty remain major public health concerns in Tanzania (Kikuli \& Mbando, 2011; Llumpo et al., 2015; World Health Organization, 2010). Most health and social problems are preventable (Kikuli \& Mbando, 2011; Tabatabai et al., 2014; White et al., 2013; World Health Organization, 2016), yet the consequence of poor healthcare leadership contributes to a range of adverse health outcomes and inequality (Braveman, Egerter \& Williams, 2011; Chapman, 2010; Mtenga, Masanja \& Mamdani, 2016; White et al., 2013: Wilkinson \& Pickett, 2010).

Previous studies show a significant relationship between the social determinants of health, poor health conditions, and the increased health inequality in a marginalized poor population (Centers for Disease Control and Prevention, 2010; Wilkinson \& Pickett, 2010). Social and behavioral conditions cost the lives of many vulnerable populations and subject a large portion of the population to poverty due to long-term illness (Centers for Disease Control and Prevention, 2010; White et al., 2013). Evidence shows that enhancing public-private partnership leadership (PPPL) could improve mutual accountability, be cost-efficient, and increase the potential opportunity for public health integrated initiatives to promote health outcomes (Downs, Montagu, DaRita, Brashers \& Feachem, 2013; Fernandez, Cho, \& Parry, 2010; Morse, 2010; Nelly, 2012; Resnick \& Siegel, 2013; Sturchio \& Cohen, 2012; U.S. Government Tanzania, 2011).

People in rural and marginalized communities in Tanzania, approximately $75 \%$ of the population, struggle to access quality, publicly available primary health and social services (Federal Ministry for Economic Cooperation and Development, 2013; Hess, Schramm, \& Luber, 2014; U.S. Government Tanzania, 2011; White et al., 2013). Inadequate information on monitoring and evaluation of PPP health interventions limits insight to quality decisions, which impacts health improvement and coverage of primary health care (Chreim, Williams, Janz, \& Dastmal, 2010; Ichoku, Mooney \& Ataguba, 2013; Levitt, 2013; White et al., 2013). Literature indicates that a lack of adequate information on primary health services and monitoring from PPP in health limits decisions on the fundamental improvement of health service coverage (Global Health Group, 2010; Itika, et al., 2011; Straus, Tetron \& Graham, 2011; U.S. Government Tanzania, 2011). Limited data on PPP leadership contributes to the lack of understanding, limited shared best practice, and lack of awareness of the benefits of PPPL (Itika et al., 2011; Tomlinson, Hewitt \& Blackshaw, 2013).

In Tanzania, the private health sector plays a vital role in promoting the health and well-being of the population. However, lack of evidence and shared best practices on PPPs limit innovative 
implementation of primary health care to support partnership (Baker et al., 2013; Itika, 2011

Mtenga et al., 2016; White et al., 2013). As such, LS is required to enhance ownership and accountability of service delivery and data management (Baker et al., 2013; White et al., 2013) for PPP in a partnership setting. The shared information provides insight into quality decision-making and improves monitoring of health interventions (Cramm et al., 2013; Kellam, 2012; Mburu et al., 2013; Silvia \& McGuire, 2010).

The literature showed no qualitative empirical evidence on partnership LS in the developing nations. Further, the evidence presented leaders and managers with different perceptions on PPP interventions (Barnes, Curtis, Hall-Downey \& Ford, 2013; Barnes, Curtis, Hall-Downey, \& Moonesignhe, 2012; Itika et al, 2011; Osei-Kyei \& Chan, 2015). Limited insight into best-practice PPP in primary health care initiatives in a community setting was a challenge (Cramm et al., 2013; Itika et al., 2011). A lack of awareness and engagement of community leaders on PPP and their benefits from participating in PPP was the gap that this research contributed to the literature. The results of this study would contribute to filling the gap in the literature about PPPL synergy with a view of improving health outcomes through the promotion of ownership and accountability in primary health care interventions and leadership.

\section{Purpose of the study}

The purpose of this study was to understand factors that would enhance partnership LS to promote ownership and accountability of health and social care initiatives in Tanzania with a view of improving health outcome of the population. Three research questions focused on the perceptions of public and private community health leaders in Tanzanian toward PPPL synergy, perceptions about facilitating LS for PPP in health interventions in a community setting, and understanding how leaders facilitate synergy for action health and social care interventions implementation in a partnership setting.

\section{Methodology}

\section{Design}

This qualitative inquiry used an empirical case study approach (Creswell, 2014; Patton, 2014). The approach provided descriptive insight into the perceptions of community leaders and managers of semiurban populations toward PPP leadership in health and social cares interventions. Diffusion of innovation framework (Glanz, Rimer \& Viswanath, 2008) and the public-private integrated module (Llumpo et al., 2015; Salvail, Turchet, Wattling \& Zhang, 2015) were used to guide data collection and analysis.

\section{Sampling}

Sampling took place among local government organizations (public sector, $n=3$ ) and not-for-profit organizations (private sector, $n=3$; Palinkas et al., 2013; Patton, 2014). Equally, four to five leaders and managers from each organization were purposefully recruited to provide in-depth information. A total of $n=26$ participants were one-on-one interviewed, and relevant documents were reviewed.

\section{Data Analysis}

A directed content analysis approach was used to review data collected and analyze the text (Miles, Huberman \& Saldana, 2014; Yin, 2017). Similarly, the theoretical framework for this study guided 
the coding process (Bucker \& Poutsman, 2010; Creswell, 2014: Miles et al., 2014). NVivo Version 11 was employed to facilitate data management and analysis (Miles et al., 2014).

\section{Results}

This study's findings were based on in-depth, one-on-one interviews with 26 participants (privatesector organizations, $\mathrm{n}=11$ [42.3\%]; public-sector organizations, $n=15$ [57.7\%]). The researchers were interested in understanding the factors that could promote partnership LS to enhance ownership and accountability of PPP in health and social care interventions to improve the health outcome of the population. As presented in Table 1, the findings indicate that integrated supportive supervision, teamwork, and strategic communication promote partnership LS.

Table 1. Factors That Promote Partnership Leadership Synergy

\begin{tabular}{|c|c|c|c|}
\hline \multirow[b]{2}{*}{$\begin{array}{l}\text { Common } \\
\text { emerged theme }\end{array}$} & \multicolumn{2}{|c|}{$\begin{array}{c}\text { Emerged theme by specific } \\
\text { sector, } n(\%)\end{array}$} & \multirow[b]{2}{*}{$\begin{array}{c}\text { Total } \\
\text { emerged } \\
\text { theme, } n(\%)\end{array}$} \\
\hline & Public sector & $\begin{array}{l}\text { Private } \\
\text { sector }\end{array}$ & \\
\hline Integrated supportive supervision and meeting & $18(78.3 \%)$ & $5(19.2 \%)$ & $23(88.5 \%)$ \\
\hline Teamwork & $11(42.3 \%)$ & $8(30.8 \%)$ & $19(73.1 \%)$ \\
\hline Strategic communication & $3(11.5 \%)$ & $3(11.5 \%)$ & $19(73.1 \%)$ \\
\hline
\end{tabular}

On the other hand, Table 2 shows that a lack of clear roles and responsibilities, poor quality data, and lack of understanding the benefit of PPP in health at the community level hinder ownership and accountability in the implementation of PPP interventions.

Table 2. Factors That Hinder Partnership Leadership Synergy

\begin{tabular}{llll} 
& \multicolumn{2}{c}{$\begin{array}{c}\text { Emerged theme by specific } \\
\text { sector, } n(\%)\end{array}$} & $\begin{array}{c}\text { Total } \\
\text { emerged }\end{array}$ \\
\cline { 2 - 3 } Common & \multicolumn{2}{c}{$\begin{array}{c}\text { Public sector } \\
\text { emerged theme }\end{array}$} & $\begin{array}{c}\text { Private sector } \\
\text { theme, } n(\%)\end{array}$ \\
\hline Unclear roles and responsibilities & $7(26.9 \%)$ & $5(19.5 \%)$ & $6(23.1 \%)$ \\
$\begin{array}{l}\text { Lack of data quality and linkages } \\
\text { Limited understanding of public- } \\
\text { private partnerships benefit }\end{array}$ & $6(23.1 \%)$ & $5(19.2 \%)$ & $11(42.3 \%)$ \\
\hline
\end{tabular}

\section{PPP Leaders' Perceptions Toward Partnership Leadership Synergy}

The study findings revealed that $88.5 \%$ of public and private leaders and managers of PPP perceived that LS is a good practice. Findings indicate that the integrated supportive supervision initiatives and meetings provided a platform on which both leaders share the plan and implement the result as a team in a harmonized setting. Public-sector PPP leaders and managers commented that "together we can identify the gap, and mutually we increase our cooperation" and this has "increased trust and feeling of fairness" because both coordinators visit the center, and if there are any problems, both sides see it without bias from one side. Furthermore, $73.1 \%$ of both private and public PPP leaders perceived that a strategic communication approach increases positivity and may improve efficiency in the implementation of partnership LS approach. On the other hand, the private-sector leaders feel that advocacy to improve teamwork among community PPP leadership is required because, still, the 
public sector is not clear on the roles and responsibilities of PPP at the community setting and slimly engaging the private-sector primary health providers in PPP leadership decisions. Moreover, 46.9\% of both private- and public-sector leaders feel that they have a limited understanding of the PPP approach and its benefit. The private sector highlighted that the lack of clear understanding of PPP roles and responsibilities brings confusion in the implementation of PPP in primary health interventions. Four leaders of public and private sector raised their concern that although the government assumes full responsibility of PPP implementation, they think it should be two-way traffic and the municipality needs to open doors, work together as a team, and engage more privatesector leaders. Both parties believe that the partnership LS in the municipality can be a challenge because of lots of bureaucracy. The private sector brought up the concerns that the partnership leadership at the national level assumed a practical approach but at the community, PPP leadership would need capacity building and empowerment to enhance functionality.

\section{Leaders Perceptions to Facilitate Leadership Synergy in PPP}

This study found three main factors that would facilitate LS to enhance ownership and accountability in the implementation of PPP primary health interventions. These factors are teamwork, integrated supportive supervision, and strategic communication. The finding means that the teamwork increased coverage of some of the primary care delivery in remote areas. Examples of visible outcomes of the teamwork interventions are tuberculosis and leprosy screening and increased access to long-term family planning methods that are provided by both the public and the private sector in a partnership setting. Integrated supportive supervision involved both the private and public sectors in the provision of reproductive health, which harmonizes relationships and minimizes duplication of services in the community. Further, the findings show that the integrated supportive supervisions lack full engagement of community health leaders at the municipal level. Strategic communication among leaders improves collaboration and irons out misunderstandings among partners. Conversely, the local government health management team holds full responsibilities of PPPL. Moreover, this study found that although the municipal health management team engages private-sector health entities in integrated planning meetings, the engagements do not involve decision-making on PPP interventions in the community setting.

\section{Facilitation of Synergy for Action PPP Interventions}

This study found factors that hinder ownership and accountability of PPP in primary health implementation in a partnership setting: Both public and private sectors demonstrated a limited understanding of how PPP in primary care is designed, built, and financed at the community level. The public sector at the community level lacks clear roles and responsibilities of leaders in the implementation of PPP interventions. PPP policy and guideline reviews are conducted at the national level; the primary care providers at the community level are not fully represented. Leaders encounter ineffective planning due to unclear data linkages and poor data quality at the community level. Moreover, this study found there are many training programs on PPP; these programs are functioning at the national level and in one district council, the Ilala Municipal. Also, the results from this study show that the awareness and stability of PPP leadership vary across the three study areas, which are Dar Es Salaam Municipal councils. For example, Kinondoni and Temeke district councils experienced frequent reshuffling of district leaders and health management staff, and no clear pathway was in place for handing over the PPP implementation plan.

The reviewed documents showed that PPP in health and social welfare is well mainstreamed from the national to the ward level (Tanzania Ministry of Health and Social Welfare [MoHSW], 2013). Equally, the national PPP policy, private-sector strategic planning documents, and the faith-based 
PPP implementation plan illustrated pathways to engage partners from top to bottom in health and social care interventions (United Republic of Tanzania, 2009, 2010). According to MoHSW (2013), the regional municipal PPP health forum is responsible for synergizing PPP leadership activities at all levels. However, this study found the community PPPs in health forums are not functioning at the regional level and in the community setting. Similarly, the PPP health leadership at the community level has no budget to carry on integration strategic plans and forums. As such, this study found substantially limited knowledge on the PPP and the benefits of the PPP at the community level, which impedes the ownership and accountability of the PPP health interventions. The document review shows that the lack of knowledge is underpinned by the national policy guideline, which pointed out the existence of a lack of clear understanding of the benefit of PPP in health at the community level (MoHSW, 2013).

\section{Discussion}

\section{Application}

The concept of PPP has been adopted to facilitate the delivery of health and social welfare services with the intention of improving health outcome of the population (Bulk \& Gregory, 2013; Cappellaro \& Longo, 2011; Eschenfelder, 2011; MoHSW, 2013: Montagu \& Harding, 2012: Spreng, 2011; Sturchio \& Cohen, 2012). The PPP is the agreement between the government, public sector, and private sector to deliver services for the public use. Promoting the ownership and accountability of the delivery of health and social services between these partnerships is vital to ensure access, quality of care, continuity, and cost efficient (Ansari, 2012; Forrer, Kee, Newcomer \& Boyer, 2010; Kharizam, Roshare \& Hadi, 2012; Sekhiri et al., 2011; Spreng, 2011; Waweru, Goodman, Kedenge, Tsofa \& Molyneux, 2016) in improving health outcomes.

The synergistic capacity in designing, monitoring, and implementing health and social services initiatives within this partnership may facilitate community engagement and ownership and promote accountability for the delivering of primary health and social care initiatives (Ansari, 2012; Basu, Andrew, Kishore, Panjabi \& Stuckler, 2012; Kellam, 2012) to improve health outcome of the population. The stigma and negative perception toward community PPPL in health care interventions implementation is a challenge (Brassolotto, Raphael, \& Baldeo, 2014; Cramm et al., 2013; Jones \& Barry, 2011; Levitt, 2013). Increased awareness and understanding of the benefit of PPP at the community level would promote ownership and accountability. Significant evidence on limited data on LS contributes to the lack of understanding, limited shared best practice, and limited awareness of the benefits of public health leadership (Crosby \& Bryson, 2010; Itika et al., 2011; Weiss et al., 2010). Further, limited qualitative and quantitative literature on partnership LS in developing nations limits the evidence on community engagement and effective decisions on the planning of the community health and social welfare interventions. Given the challenges of the designing and monitoring process of PPP projects, ownership and accountability of the implementation of the primary health and social welfare initiatives at the community setting suffer significantly (Cramm et al., 2013; Ingram, Schtchfield, \& Costich, (2015); Itika et al., 2011; Jones \& Barry, 2011).

\section{Limitations}

This empirical case study explored the perceptions of leaders and managers of public and private not-for-profit organizations toward LS in a partnership setting in Tanzania. The focus was on primary health care implementation. Therefore, a generalization of the study findings is limited to 
the participants and study population. However, the researchers believe there is relevance to similar partnerships on other settings and communities.

\section{Recommendations}

The results of this study indicate significant evidence of promoting accountability and ownership through enhancing LS between public and private or private and private partnerships in the implementation of primary health care interventions in a partnership setting to improve health outcomes. Further research is recommended to explore the perceptions of the public-private sector for profit in the implementation of primary health care intervention in a partnership setting at the community level. Also, the national and technical PPP team should advocate for an inclusive policy for the implementation of primary health care in a partnership setting to improve health outcomes in the remote area.

\section{Conclusion}

The PPP LS is the alliance between leaders of the public and private organizations to implement health and social care interventions in a partnership setting. To a varying extent, the municipal councils - the public partner-assume the overall leadership role of all health and social interventions within the municipality. This study found that the private sector provides a broad range of health services, reaching remote area populations with limited community leadership engagement at the municipal level. The provision of primary health care, that is, publicly free consumed health interventions, requires not only integrated supervision leadership activity, but also role specification to promote accountability and ownership in a partnership setting.

The findings indicated that integrated supportive supervision, teamwork, and strategic communications promote partnership LS. They also showed that a lack of clear roles and responsibilities, poor quality data, limited understanding of the benefits of PPP in health at the community level hinder ownership and accountability in the implementation of PPP interventions. The findings of this study may influence positive social change through facilitative diffusion of LS practice policy. Also, the insight from this study could increase awareness of the benefit of PPP at the community level, which would promote more engagement of stakeholders that, in turn, would foster ownership and accountability of primary health care interventions to improve health and promote positive social change.

\section{References}

Ansari, W. E. (2012). Leadership in community partnerships: South African study and experience. Journal of Public Health, 20, 174-184.

Baker, E., Barnidge, E. M., Langston, M., Schoolman, M., Motton, F. \& Frank, R. (2013). Leadership and job readiness: Addressing social determinates of health among rural African American men. International Journal of Men's Health, 12, 245-259.

Barnes, P., Curtis, A., Hall-Downey, L., \& Ford, L. (2013). Community partners' perceptions in working with local health departments: An exploratory study. International Journal of Qualitative Research in Services, 1, 35-52.

Barnes, P. Curtis, A., Hall-Downey, L., \& Moonesignhe, R. (2012). A multistate examination of partnership activities among local public health system using the National Public Health Performance Standards. Journal of Public Health Management and Practice. 18, 14-23. 
Basu, S., Andrew, J., Kishore, S., Panjabi, R., \& Stuckler, D. (2012). Comparative performance of private and public health care system in low and middle income countries: A system review. PLoS Med, 9, e1001244. doi:10.1371/journal.pmed.1001244

Brassolotto, J., Raphael, D., \& Baldeo, N. (2014). Epistemology barriers to addressing the social determinants of health among public health professionals in Ontario, Canada: A qualitative inquiry. Critical Public Health, 24, 321-336.

Braveman, P., Egerter, S., \& Williams (2011). The social determinants of health: Coming of age. Annual Review of Public Health, 32, 381-398.

Bucker, J., \& Poutsman, E. (2010). Global management competencies: A theoretical foundation. Journal of Management Psychology, 32, 829-844.

Bulk, D., \& Gregory, S. (2013). The king's fund: Improving the public's health: A resource for local Authority. Retrieved from http://www.improvingthepublic-health-kingsfund-doc13

Cappellaro, G., \& Longo, F. (2011). Institutional public private partnership for core health services: Evidence from Italy. BMC health Service Research, 11, 82-90.

Centers for Disease Control and Prevention. (2010). Healthy people 2020: Improving health of the nation. Washington, DC: Author.

Chapman, A. R. (2010). The social determinant of health, health equity, and human rights. Health and Human Rights, 12, 17-30,

Chreim, S., Williams, B., Janz, L., \& Dastmal, C. A. (2010). Change agency in a primary care context: the case of distributed leadership. Health Care Management, 35, 187-199.

Cramm, J. M., Phaff, S., \& Nieboer, A. P. (2013). The role of partnership functioning and synergy in achieving sustainability of innovative programs in community care. Health and Social Care in the Community, 21, 209-215.

Creswell, J. W. (2014). Research design: Qualitative, quantitative and mixed research approaches (4th ed.). Washington, DC: Sage.

Crosby, B. C., \& Bryson, J. M. (2010). Integrative leadership and the creation and maintenance of cross sector collaboration. The Leadership Quarterly, 21, 211-230.

Curry, L., Taylor, L., Chi-Chen, P. G., \& Bradley, E. (2012). Experiences of leadership in health care in sub-Sahara Africa. Human resources for Health, 10, 33. doi:10.1186/1478-4491-10-33

Downs, S., Montagu, D., Da Rita, P., Brashers, E., \& Feachem, R. (2013). Health system innovation in Lesotho: Design and early operations of the Maseru public-private integrated partnership (Healthcare Public-Private Partnerships Series, No. 1). San Francisco, CA: The Global Health Group, Global Health Sciences, University of California, San Francisco, and PwC.

Eschenfelder, B. (2011). Funder-initiated integration partnership challenges and strategies. NonProfit Management and Leadership, 21, 273-288.

Federal Ministry for Economic Cooperation and Development. (2013). Cooperation with the private sector in Tanzania (Country Report 2013). Eschborn, Germany: Deutsche Gesellschaft für Internationale Zusammenarbeit. Retrieved from https://www.giz.de/fachexpertise/downloads/giz2013-en-tanzania-country-report.pdf

Fernandez, S., Cho, Y. J., \& Parry, J. L. (2010). Exploring the link between integrated leadership and public sector performance. The Leadership Quarterly, 21, 308-323. 
Forrer, J., Kee, J. E., Newcomer, K. E., \& Boyer, E. (2010). Public-private partnership and the public accountability question: Seminal questions facing contemporary public organisations. Public Administration Review, 70, 475-484. doi:10.111/j.1540-6210.2010.02161.x

Glanz, K., Rimer, B. K., \& Viswanath, K. (Eds.). (2008). Health behavior and health education: Theory, research, and practice (4th ed.). San Francisco, CA: John Wiley \& Sons.

Global Health Group. (2010). Public private innovation partnership for health: An atlas of innovation. San Francisco, CA: Author.

Hess, J., Schramm, P., \& Luber, G. (2014). Public health and climate change adaptation at the federal level: One agency's response to Executive Order 13514. American Journal of Public Health, 104, e22-e30.

Ichoku, H. E., Mooney, G., \& Ataguba, J. E. O. (2013). Africanising the social determinant of health: Embedded structure inequality and current health outcomes in sub-Sahara Africa. International Journal of Health Services, 43, 745-759.

Ingram, R., Schtchfield, F. D., \& Costich, J. F. (2015). Public health department and accountable care organisation: Finding common ground in population health. American Journal of Public Health, 105, 840-846.

Itika, J., Mashindano, O., \& Kessy, F. (2011). Success and constraints for improving public private partnership in health services delivery in Tanzania (Discussion Paper No. 36). Dar es Salaam, Tanzania: Economic and Social Research Foundation. Retrieved from http://esrf.or.tz/docs/ESRFDiscussionPaper36.pdf

Jones, J., \& Barry, M. M. (2011). Exploring the relationship between synergy and partnership functioning factors in health promotion partnership. Health Promotion International, 26, 408-420. doi:10.1093/heapro/dar002

Kellam, S. G. (2012). Developing and maintaining partnership as the foundation of implementation and implementation science: Reflections over a half a century. Administration Policy Mental Health, 39, 317-320. doi:10.1007/s10488-011-0402-8

Kharizam, I., Roshare, T., \& Hadi, N. A. (2012). A public sector comparison (PSC) for value for money (VFM) assessment tool. Asian Social Science, 8, 192-201.

Kikuli, R., \& Mbando, D. (2011). Health sector and social welfare public and private partnerships policy guidelines. Dar es Salaam, Tanzania: Tanzania Ministry of Health and Social Welfare.

Kwesigabo, G., Mwangu, M. A., Kakoko, D. C., \& Killewo, J. (2012). Health challenges in Tanzania: Context for educating health professionals. Journal of Public Health Policy, 33, 523-534.

Levitt, M. (2013). Perceptions of nature nurture and behaviour. Life Sciences, Society and Policy, $9,13$.

Llumpo, A., Montagu, D., Brashers, E., Foong, S., Abuzaineh, N., \& Feachem, R. (2015). Lessons from Latin America: The early landscape of healthcare public-private partnerships (Healthcare Public-Private Partnership Series, No. 2). San Francisco, CA: The Global Health Group, Global Health Sciences, University of California, San Francisco, and PwC.

Mburu, G., Oxenham, D., Hodgson, I., Nakiyemba, A., Seeley, J., \& Bermejo, A. (2013). Community system strengthening for HIV care: Experience from Uganda. Journal of Social Work in Endof-Life \& Palliative Care, 9, 343-368.

Miles, M, B., Huberman, A. M., \& Saldana, J. (2014). Qualitative data analysis: A Methods sourcebook (3rd ed.). Thousand Oaks, CA: Sage. 
Montagu, D., \& Harding, A. (2012). A zebra or a painted horse? Are hospital PPPs infrastructure partnerships with strips or a separate species? World Hospital health Services, 48, 15-19.

Morse, R. (2010). Integrative public leadership: Catalysing collaboration to create public value. The Leadership Quarterly, 21, 231-245.

Mtenga, S., Masanja, I., \& Mamdani, M. (2016). Strengthening national capacity for researching on social determinants of health (SDH) toward informing and addressing health inequalities in Tanzania. International Journal for Equity in Health, 15, 1-10.

Nelly, A. (2012). Health Promotion Award 2011: Recognizing today's health promotion. Perspective in Public Health, 132, 14-15.

Osei-Kyei, R., \& Chan, A. P. (2015). Review of studies on the critical success factors for PPP project 1990-2013. International Journal of Project Management, 33, 1335-1346. doi:10.1016/j.iproman.2015.02.008

Palinkas, L., Horwitz, S., Green, C. A., Wisdom, J., Duan, N., \& Hongwood, K. (2013). Purposeful sampling for qualitative data collection and analysis in mixed method implementation research. Administration and Policy in Mental Health and Mental Health Services Research, 42, 533-544. doi:10.1007/s10488-013-0528-Y

Patton, M. Q. (2014). Qualitative research and evaluation methods (3rd ed.) Thousand Oak, CA: Sage.

Resnick, E. D., \& Siegel, M. (2013). Marketing public health: Strategies to promote social change (3rd ed.). Burlington, MA: Jones \& Bartlett Learning.

Salvail, L., Turchet, L., Wattling, D., \& Zhang, C., (2015). Public-Private-Partnerships: Putting P3 funding models to work for health IT (CHIEF discussion paper). Toronto, Canada: Canada's Health Informatics Association. Retrieved from http://www.mi2health.com/wpcontent/uploads/2015/10/Discussion-Paper-Public-Private-Partnerships-3.pdf

Sekhiri, N., Feachem, R., \& Ni, A. (2011). Public-private integrated partnerships demonstrate the potential to improve health care access, quality, and efficiency. Health Affairs, 30, 14981507.

Silvia, C., \& McGuire, M. (2010). Leading public sector networks: An empirical examination of integrative leadership behaviour. The leadership Quarterly, 21, 264-277.

Spreng, C. P. (2011). Healthy partnerships: How governments can engage the private sector to improve health in Africa. Washington, DC: World Bank.

Straus, S. E., Tetron, J. M., \& Graham, I. D. (2011). Knowledge translation is the use of knowledge in health care decision-making. Journal of Clinical Epidemiology, 64, 6-10.

Sturchio, J. L., \& Cohen, G. M (2012). How PEPFAR'S public-private partnerships achieved ambitious goals, from improving labs to strengthening supply chains. Health Affairs, 31, $1450-1458$.

Tabatabai, P., Henke, S., Susac, K., Kisanga, O. M. E., Baumgarten, I., Kynast-Wolf, G., . . Marx, M. (2014). Public and private maternal health service capacity and patient flows in southern Tanzania: Using a geographic information system to link hospital and national census data. Global Health Action, 7, 1. doi:10.3402/gha.v7.22883

Tanzania Ministry of Health and Social Welfare (MoHSW). (2013). Public private partnership: Training manual for health and social welfare stakeholders. Dar es Salaam, Tanzania: Author. 
Tomlinson, P., Hewitt, S., \& Blackshaw, N. (2013). Joining up health planning: How joint strategies need assessment (JSNA) can inform health and well-being strategies and spatial planning. Perspective in Public Health, 133, 254-262.

United Republic of Tanzania. (2009). National public-private partnership (PPP) policy. Dar Es Salaam, Tanzania: Author. Retrieved from http://tanzania.eregulations.org/media/PPP\%20Policy.pdf

United Republic of Tanzania. (2010). Public-Private Partnership Act. Dar Es Salaam, Tanzania: Author. Retrieved from http://tanzania.eregulations.org/media/PPP\%20Act.pdf

U.S. Government Tanzania. (2011). Tanzania Global Health Initiatives strategy 2010-2015. Dar es Salaam, Tanzania: Author.

Waweru, E. Goodman, C., Kedenge, S., Tsofa, B., \& Molyneux (2016). Tracking implementation and (un)intended consequences: A process evaluation of an innovative peripheral health facilities financing mechanism in Kenya. Health Policy and Planning, 31, 137-147.

Weiss, E. S., Taber, S. K., Breslau, E. S., Lillie, S. E., \& Li, Y. (2010). The role of leadership and management in six southern public health partnerships: A study of member involvement and satisfaction. Health Education and Behaviour, 37, 737-752.

White, J., O’Hanion, B., Chee, G., Malangalila, E., Kimambo, A., Coarasa, J., . . McKeon, K. (2013). Tanzania private sector assessment. Bethesda, MD: Strengthening Health Outcomes Through the Private Sector Project, Abt Associates.

Wilkinson, R., \& Pickett, K. (2010) The spirit level: Why greater equality makes society stronger. New York, NY: Bloomsbury Press.

World Health Organization. (2010). Action on the social determinants of health: Case studies, learning from previous experience. Geneva, Switzerland: Author.

World Health Organization. (2016). Sustainable development goals (SDG): Goal 17: Strengthening The Means of Implementation and Revitalize The Global Partnership For Sustainable Development. Geneva, Switzerland: Author.

Yin, R. K. (2017). Case study research and application: Design and methods (6th ed.). Thousand Oaks, CA: Sage.

The Journal of Social Change, sponsored by Walden University, welcomes manuscripts focusing on interdisciplinary research in social change that improves the human condition and moves people, groups, organizations, cultures, and society toward a more positive future.

Walden University Publishing: http://www.publishing.waldenu.edu 